\title{
Removal of the endocrine disrupter butyl benzyl phthalate from the environment
}

\author{
Subhankar Chatterjee $\cdot$ Petr Karlovsky
}

Received: 27 January 2010 /Revised: 16 March 2010 /Accepted: 17 March 2010 /Published online: 16 April 2010

(C) The Author(s) 2010. This article is published with open access at Springerlink.com

\begin{abstract}
Butyl benzyl phthalate (BBP), an aryl alkyl ester of 1,2-benzene dicarboxylic acid, is extensively used in vinyl tiles and as a plasticizer in PVC in many commonly used products. BBP, which readily leaches from these products, is one of the most important environmental contaminants, and the increased awareness of its adverse effects on human health has led to a dramatic increase in research aimed at removing BBP from the environment via bioremediation. This review highlights recent progress in the degradation of BBP by pure and mixed bacterial cultures, fungi, and in sludge, sediment, and wastewater. Sonochemical degradation, a unique abiotic remediation technique, and photocatalytic degradation are also discussed. The degradation pathways for BBP are described, and future research directions are considered.
\end{abstract}

Keywords Endocrine disrupter $\cdot$ Phthalate $\cdot$ Butyl benzyl phthalate $\cdot$ Biodegradation $\cdot$ Monoesters $\cdot$ Degradation pathway

\section{Introduction}

With the growth in both human population density and industrial activity over the last decades, the quantity of man-made (xenobiotic) compounds released into the environment has greatly increased (CERHR 2000). Chemical and pharmaceutical industries produce a wide array of xenobiotics, especially plasticizers and synthetic polymers,

\section{S. Chatterjee $(\triangle) \cdot$ P. Karlovsky}

Molecular Phytopathology and Mycotoxin Research Unit, University of Goettingen,

Grisebachstrasse 6,

37077 Goettingen, Germany

e-mail: sc_gottingen@yahoo.com while pulp and paper bleaching industries are the main sources of the chlorinated organic compounds. Although the demands of the approval processes and regulation governing the release of xenobiotics have been growing continuously during the last two decades, unforeseen consequences of the release of man-made chemicals into the environment have recently been discovered. One of these effects is the disturbance of the mammalian endocrine system by compounds that bind to estrogen receptors. The effects of man-made chemicals on the endocrine system have been studied for decades, but their relevance for human health has only recently been acknowledged. Man-made endocrine disruptors (EDs) can interfere with hormones by mimicking hormones, blocking hormone receptors, or altering hormone metabolism (Gilbert 2006). EDs are now regarded as the most dangerous pollutants by environmental protection agencies around the world.

Health agencies and scientists are deeply concerned about the exposure of humans to EDs, which are now widely distributed in the environment (Carlsen et al. 1992; Hewitt et al. 2007; Jiao et al. 2007; Safe 2004). Nonsteroidal EDs are less powerful than steroidal EDs but are produced in much larger quantities. The best known EDs are phthalates, hexachlorocyclohexane (lindane), pentachlorophenol, DDT, bisphenol A, atrazine, dioxins, furans, poly-chlorinated biphenyls, and also some heavy metals (Dyer 2007). Natural products with estrogenic activities such as plant-based phytoestrogens and resorcylic acid lactone mycotoxins are also regarded as EDs.

One of the most important classes of EDs are esters of phthalic acid (1,2-benzenedicarboxylic acid) or phthalates, which are ubiquitous in the environment. Phthalates have been found in sediments, natural waters, soils, and aquatic organisms (Giam et al. 1984; Staples et al. 1997), and also in drinking water, air, and food (ATSDR 1995, 2000). 
Globally, more than 18 billion pounds of phthalates are used each year primarily as plasticizers in flexible polyvinyl chloride (PVC) products (Blount et al. 2000a) and also as inert ingredients in many sprays including pesticides and in many consumer products such as cosmetics and wood finishes (Blount et al. 2000b). As plasticizers, phthalates are not tightly bound to the plastics, and they therefore leach from plastic products into the environment over time. Because of their widespread use as plasticizers, phthalates have been detected in human serum and plasma (Kato et al. 2003). Relatively high-molecular-weight phthalates do not dissolve easily in water and can accumulate in tissues of various aquatic organisms. Thus, they can accumulate in the food chain via biomagnifications as one organism consumes food lower in the chain and is subsequently consumed by an organism higher in the chain; humans are generally at the top of such chains, and this increases their exposure.

Among phthalate esters, butyl benzyl phthalate (BBP) (Fig. 1) is one of the most important environmental contaminants with documented adverse health effects (Bornehag et al. 2004; Harris et al. 1997; Kang and Lee 2005; Liu and Chen 2006; Nakai et al. 1999; Soto et al. 1995). BBP has been tested for estrogenic properties both in vivo and in vitro (Harris et al. 1997; Jobling et al. 1995; Nativelle et al. 1999). In the recombinant yeast screen assay, BBP was the most active estrogenic phthalate among those tested (Harris et al. 1997). BBP caused developmental and testicular toxicity as well as malformations and embryonic deaths in mice and in rats (Agas et al. 2007; Ema et al. 1999; Gray et al. 2000; Piersma et al. 2000). BBP possesses significant reproductive toxicity in that it decreases sperm production, alters sexual development in neonates, and induces genomic changes in the rat mammary gland after neonatal/prepubertal exposure (Ema et al. 2003; Ema and Miyawaki 2002; Moral et al. 2007; Swan 2008). Furthermore, BBP alters the levels of testosterone and other reproductive hormones and is toxic to the testes, prostate, and seminal vesicle (NTP-CERHR 2003). Picard et al. (2001) showed that BBP was extensively metabolized by MCF-7 cells (a breast cancer cell line), resulting in the accumulation of the metabolites, mono-butyl phthalate $(\mathrm{MBuP})$, mono-benzyl phthalate (MBzP), benzoic acid,

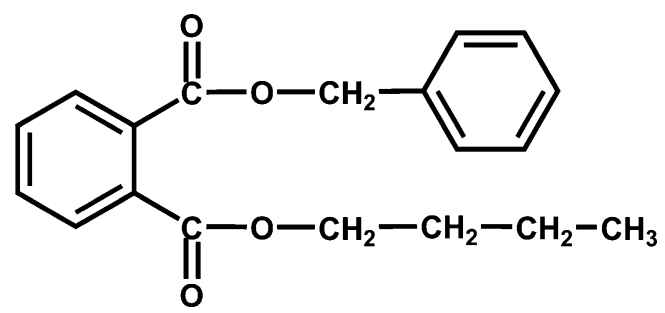

Fig. 1 Structure of butyl benzyl phthalate (BBP) phthalic acid, and hippuric acid in the medium. Prenatal exposure to $\mathrm{MBuP}$ and $\mathrm{MBzP}$ is associated with shortened anogenital distance in male infants of humans (Swan et al. 2005). BBP and its monoesters also participate in the induction of antiandrogenic and teratogenic effects in rats (Ema and Miyawaki 2002, and references therein). A twogeneration reproductive study with male and female Sprague-Dawley rats showed that BBP exposure reduced the weight of the ovaries in adult females and the body weights in newborns and modified anogenital distances in both male and female pups (Nagao et al. 2000). A recent report on toxicity tests with two-stage embryos of the marine univalve Haliotis diversicolor supertexta showed that BBP was the most toxic among the seven phthalates tested (Liu et al. 2009). In humans, BBP was suspected to increase the severity of endometriosis (Reddy et al. 2006).

According to the American Chemistry Council (ACC, formerly CMA) (CMA 1999), the largest use of BBP is in vinyl tile. BBP is also used as a plasticizer in PVC-based food conveyor belts, carpet tiles, artificial leather, tarps, automotive trim, weather stripping, traffic cones, and to a limited extent in vinyl gloves (IPCS 1999). The compound is also a component of some adhesives, cellulose plastics, and polyurethane (IPCS 1999). As an environmental contaminant, BBP is usually released into the air in the form of dust. BBP may be released to the air through the combustion of refuse (Graedel et al. 1986), and it has also been detected in stack emissions from hazardous waste combustion facilities and from coal burning power plants in the USA (Oppelt 1987). Once in the atmosphere, BBP spreads and can subsequently be detected in the atmosphere, soil, surface water, and sediments (CICAD 1999).

Increased awareness of the harmful effects of EDs has led to a dramatic increase in research on methods to remove these compounds from the environment. One of the most studied methods of removal is bioremediation, which involves the enzymatic degradation of pollutants by living organisms. Compared to non-biological methods, the great versatility of microorganisms represents a simpler, less expensive, and more environmentally friendly method for reducing environmental pollution. In the following, we describe recent developments in strategies for the removal of BBP from the environment.

\section{Degradation of BBP}

Degradation by pure bacterial cultures

Degradation of BBP has been reported for bacteria of three divisions, namely Proteobacteria, Actinobacteria (high GC content), and Firmicutes (low GC content). Strains degrading BBP belong to the genera Sphingomonas ( $\alpha$-Proteobacteria), 
Pseudomonas ( $\gamma$-Proteobacteria), Corynebacterium (Actinobacteria), Gordonia (Actinobacteria), Arthrobacter (Actinobacteria), Enterococcus (Firmicutes), and Bacillus (Firmicutes). All these genera are obligatory aerobic; anaerobic degradation of BBP by bacteria in pure culture has not been reported yet.

Chatterjee and Dutta (2003) described degradation of BBP by a Gram-positive bacterium, Gordonia sp. strain MTCC 4818, isolated from creosote-contaminated soil. The strain hydrolyzed both ester bonds of BBP, utilized the released benzyl alcohol and butanol for growth, and was able to use BBP as a sole source of carbon and energy. The esterase activity was induced by BBP, and phthalic acid accumulated as an end product in the medium. MTCC 4818 degraded $1 \mathrm{~g} / \mathrm{L}$ of $\mathrm{BBP}$ at neutral $\mathrm{pH}$ and at $28^{\circ} \mathrm{C}$ within 4 days, but the degradation of monoesters $\mathrm{MBuP}$ and $\mathrm{MBzP}$ was considerably slower, and these compounds accumulated in the spent culture in a 1:2 ratio.

Corynebacterium sp. DK4, which was isolated from river sediment, and Sphingomonas sp. O18, which was isolated from petrochemical sludge, completely degraded BBP $(5 \mathrm{mg} / \mathrm{L})$ in batch culture at $30^{\circ} \mathrm{C}$ and at $\mathrm{pH} 7$ under aerobic conditions within 2 and 3 days, respectively (Chang et al. 2004). Corynebacterium sp. DK4 degraded $\mathrm{BBP}$ under a wide range of conditions, including temperatures from $20^{\circ} \mathrm{C}$ to $40^{\circ} \mathrm{C}$ and neutral to alkaline $\mathrm{pH}$ values. Strain DK4, however, could only utilize low concentrations $(5 \mathrm{mg} / \mathrm{L})$ of BBP; higher concentrations of BBP (30 and $100 \mathrm{mg} / \mathrm{L}$ ) remained unaffected in the medium even after 7 days of incubation, indicating that high phthalate concentrations were toxic to the bacterium. DK4 degraded a mixture of eight phthalates much faster than single phthalates because the mixtures provided a greater range of carbon and energy sources. The authors confirmed their in vitro results with soil experiments (Chang et al. 2002), and they found that Sphingomonas sp. O18 could also degrade BBP but more slowly than DK4.

The bacterium Pseudomonas fluorescens B-1, which was isolated from mangrove sediment, completely degraded BBP in vitro within 6 days over a concentration range of 2.5 to $20 \mathrm{mg} / \mathrm{L}$ at $\mathrm{pH} 7$ and $30^{\circ} \mathrm{C}$ (Xu et al. 2006). The rate of BBP degradation (at an initial concentration of $10 \mathrm{mg} / \mathrm{L}$ and $\mathrm{pH} 7$ ) increased with temperature from 20 to $37^{\circ} \mathrm{C}$. The optimum $\mathrm{pH}$, temperature, and salinity for this experiment were $7.0,37^{\circ} \mathrm{C}$, and $15 \mathrm{~g} / \mathrm{L}$, respectively. The authors assumed that the degradation process could be fitted to a first-order kinetic model. The major metabolites found during the course of degradation were MBuP, MBzP, phthalic acid, and benzoic acid. Like Gordonia sp. strain MTCC 4818 (Chatterjee and Dutta 2003), P. fluorescens B-1 utilized the butyl group moiety of BBP more readily than the benzyl moiety (Xu et al. 2006).
Chang et al. (2007) isolated bacteria from sludge samples and found 11 aerobic strains capable of metabolizing the following phthalates as carbon sources: BBP, diethyl phthalate (DEP), dibutyl phthalate (DBP), and diethyl hexyl phthalate (DEHP). The most effective strains were Enterococcus sp. OM1, Bacillus benzoevorans (S4), and one unidentified strain (OM5). These three strains reduced the amount of $\mathrm{BBP}$ in the medium by $98.6 \%$ to $100 \%$ within 5 days of incubation. Degradation by these three strains was comparable to that by Sphingomonas sp. O18 and Corynebacterium sp. DK4 (Chang et al. 2004).

Arthrobacter sp. WY, which was isolated from municipal waste-contaminated soil, degraded 50\% BBP (initial concentration $1 \mathrm{~g} / \mathrm{L}$, at $\mathrm{pH} 7$ and $28^{\circ} \mathrm{C}$ ) within 16 days and 95\% within 39 days; no BBP was detected after 44 days (Chatterjee and Dutta 2008a). The slow utilization of BBP was believed to reflect the poor transport behavior of the substrate due to its hydrophobic nature. The authors suggested that the cell surface hydrophobicity of strain WY was very low, which reduced the contact with the hydrophobic substrate and thereby slowed down the degradation in the aqueous medium. The addition of Tween 80 at $0.05 \mathrm{mM}$ increased the rate of BBP degradation by almost twofold, and total degradation was accomplished within 20 days (Fig. 2). Interestingly, the strain could not utilize the side-chain alcohols (benzyl alcohol and butanol) released from BBP as carbon sources, but it could utilize both the monoesters (MBuP and MBzP) as well as phthalic

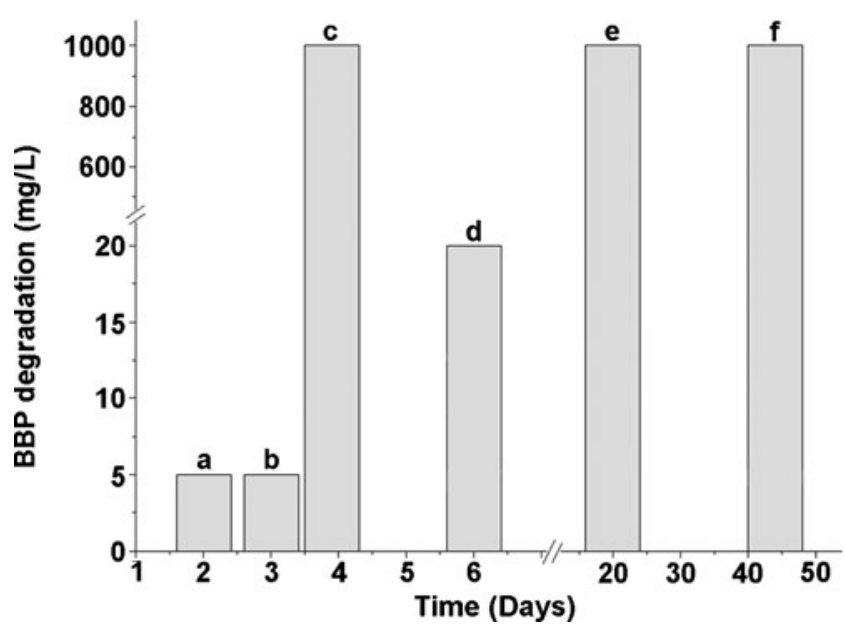

Fig. 2 Aerobic degradation of BBP by pure bacterial strains at neutral pH. Strains a Corynebacterium sp. DK4 (Chang et al. 2004); $b$ Sphingomonas sp. O18 (Chang et al. 2004); c Gordonia sp. strain MTCC 4818 (Chatterjee and Dutta 2003); $d$ P. fluorescens B-1 (Xu et al. 2006); e Arthrobacter sp. WY $+0.05 \mathrm{mM}$ Tween 80 (Chatterjee and Dutta 2008a); $f$ Arthrobacter sp. WY (Chatterjee and Dutta 2008a). Incubation temperature was $30^{\circ} \mathrm{C}$ for $a, b, d$ and $28^{\circ} \mathrm{C}$ for $c, e, f$. For strains $a-d$, values are the averages of triplicate determinations, and for $e, f$, values are the averages of triplicate determinations with the standard deviation of $\pm 5 \%$ 
acid for growth. The esterase activity was induced by BBP itself (Chatterjee and Dutta 2008b).

Figure 2 compares aerobic degradation of BBP by pure bacterial strains. Gordonia sp. strain MTCC 4818 and Arthrobacter sp. WY were the most efficient, degrading $1 \mathrm{~g} / \mathrm{L}$ of BBP. Gordonia sp. MTCC 4818 removed all BBP within 4 days (sample c) while Arthrobacter sp. WY needed 44 days (sample f). The degradation by WY was speeded up by adding Tween 80 (sample e). Corynebacterium sp. DK4 and Sphingomonas sp. O18 were only able to degrade $5 \mathrm{mg} / \mathrm{L}$ of BBP within 2 (sample a) and 3 days (sample b), respectively. P. fluorescens B-1 degraded $20 \mathrm{mg} / \mathrm{L}$ of BBP within 6 days (sample d).

\section{Degradation in sludge}

A number of studies have reported aerobic degradation of phthalates in sludge (Staples et al. 1997; Wang et al. 1997; Wang et al. 1996). In wastewater treatment plants, phthalates precipitate from the wastewater and concentrate in the sludge because of their low solubility (Bauer and Herrmann 1997). Their levels in sludge ranged from 12 to $1,250 \mathrm{mg} / \mathrm{kg}$ (Staples et al. 1997). Li et al. (2005) demonstrated that activated sludge was highly efficient in degrading BBP, i.e., more than $95 \%$ of the BBP was removed within 1 day. The authors showed that the degradation can be described by the first-order model and that the degradation rate constant decreases as the concentration of BBP increases, indicating that high concentrations of BBP inhibit its biodegradation. In sludge, BBP was first biodegraded to produce monoester, then phthalic acid, and finally $\mathrm{CO}_{2}$ and $\mathrm{H}_{2} \mathrm{O}$ (Li et al. 2005).

In another study, Chang et al. (2007) investigated the effects of ultrasonic pre-treatment, $\mathrm{pH}$, temperature, yeast extract, surfactant, and hydrogen peroxide on the aerobic degradation of four phthalates (DEP, BBP, DBP, and DEHP $)$ in sludge. Ultrasonic pre-treatment $(0.1 \mathrm{~W} / \mathrm{mL}$, $20 \mathrm{~min}$ ) increased the rate of phthalate chemical reactions in sterile sludge but much more so in nonsterile sludge. The increased effect of ultrasonic treatment in nonsterile sludge was explained by the increased activity of microorganisms. The effect of ultrasound alone can be explained by "sonochemical degradation". As described in greater detail later in this report, ultrasonic treatment of aqueous solutions generates high local temperatures and pressures in collapsing cavitation bubbles, which produce $\mathrm{OH}$ radicals and $\mathrm{H}$ atoms via pyrolysis of water. These radicals can react with organic compounds, initiating their degradation (Suslick et al. 1986; Yim et al. 2002). As documented by Chang et al. (2007), aerobic degradation of these phthalates (at initial concentrations of $50 \mathrm{mg} / \mathrm{kg}$ and at $\mathrm{pH} 7$ and $30^{\circ} \mathrm{C}$ ) followed first-order kinetics. The order of the biodegradation rates were $\mathrm{DBP}>\mathrm{BBP}>\mathrm{DEP}>\mathrm{DEHP}$. In this case, the $\mathrm{BBP}$ degradation rate constant was 0.332 /day, and the BBP half-life was 2.1 days. Only phthalic acid was identified as an intermediate of the degradation process. In this study, addition of yeast extract and surfactants (brij 30, brij 35) also increased the rate of phthalate degradation. BBP biodegradation rate was increased nearly twofold by addition of yeast extract and 1.75 -fold by addition of brij 35. The surfactants enhance degradation because the phthalates become partitioned into the surfactant's micellar phase and are then directly available to microorganisms (Santharam et al. 1997). The authors also showed that phthalate degradation at $\mathrm{pH} 7$ and $30^{\circ} \mathrm{C}$ was greater in a bioreactor experiment than in a batch experiment. Phthalate degradation was greater when phthalate was added twice (at either 100 or $1,000 \mathrm{mg} / \mathrm{kg}$ ) rather than once to the sludge sample. Half-lives of BBP were 1.2 days (after the first addition of $100 \mathrm{mg} / \mathrm{kg}$ BBP in sludge), 0.9 days (after the second addition of $100 \mathrm{mg} / \mathrm{kg}$ BBP in sludge), 6.4 days (after the first addition of $1,000 \mathrm{mg} / \mathrm{kg}$ BBP in sludge), and 1.4 days (after the second addition of $1,000 \mathrm{mg} / \mathrm{kg} \mathrm{BBP}$ in sludge). The authors concluded that combination of ultrasonic pre-treatment and biodegradation is effective for the removal of BBP and other phthalates from sludge (Chang et al. 2007).

\section{Degradation in sediments}

In both aquatic and terrestrial systems (e.g., sewage, soil, sediment, and surface water), microbial action is the principal mechanism for phthalate degradation (Staples et al. 1997). For the degradation of phthalates, both aerobic and anaerobic isolates have been described. BBP was readily biodegraded in aerobic surface water, with a halflife of 1-7 days (Saeger and Tucker 1976). Biodegradation was considerably slower in cold water, as BBP was almost completely biodegraded after 7 days in Rhine River water at $20^{\circ} \mathrm{C}$ but was not biodegraded in the same water after 10 days at $4^{\circ} \mathrm{C}$ (Ritsema et al. 1989). According to Yuan et al. (2002), six sediment samples from rivers in Taiwan contained an average of $0.2 \mu \mathrm{g}$ of $\mathrm{BBP} / \mathrm{g}$. The average biodegradation half-life of BBP in the six-river sediment samples was 3.1 days under aerobic conditions but 19.3 days under anaerobic conditions. Under both aerobic and anaerobic conditions, BBP was degraded more rapidly than its higher molecular weight counterparts (Yuan et al. 2002) because resistance of phthalates to biotransformation increases with molecular weight (Park et al. 1990).

Chang et al. (2004) quantified the degradation of eight phthalates (initial concentration of $5 \mathrm{mg} / \mathrm{L}$ and present together) in sediment by Corynebacterium sp. DK4. After 7 days of incubation, $99.2 \%$ BBP was degraded, where DEP, diphenyl phthalate (DPP), and DBP were degraded completely. Degradation was slower in sediment than in 
sediment-free culture samples (Chang et al. 2004). The slow degradation of phthalates in sediment could result from their low bioavailability, as indicated by Yuan et al. (2001) for phenanthrene degradation in river sediment. Addition of nonylphenol and five PAHs (concentration $1 \mu \mathrm{g} / \mathrm{g}$ ) to sediments retarded the degradation rate of BBP nearly three and fourfold, respectively.

In another study, Lertsirisopon et al. (2006) investigated biodegradation of DBP, BBP, DEHP, and di-isononyl phthalate (DINP) under anaerobic conditions in three natural sediments obtained from ponds in Osaka. The degradation of the four phthalates followed the first-order kinetic model with a lag phase, and the order of the degradation rates was DBP $>$ BBP $>>$ DEHP $>$ DINP. DBP and $\mathrm{BBP}$ were degraded with short lag phases and short half-lives of a few days. The result suggested that the potential for anaerobic biodegradation of phthalates is widespread in aquatic environments (Lertsirisopon et al. 2006).

\section{Degradation by mixed bacterial cultures}

It is unlikely that a single bacterium possesses all of the genes required for the complete mineralization of aryl alkyl phthalates. The degradation of BBP, for instance, requires esterase(s) specific for BBP and its monoester(s), in addition to enzymes for degradation of phthalic acid, benzyl alcohol, and $n$-butanol. Therefore, scientists are developing syntrophic bacterial consortia for complete degradation of such phthalates. In this consortium, different members are specialized in certain biodegradative steps, generating intermediates that are degraded by other members.

Chatterjee and Dutta (2008a, b) recently described two defined consortia and discussed the role of individual species for the biodegradation of BBP in vitro. The first consortium was a two-member culture developed by enrichment of local soil with BBP (Chatterjee and Dutta 2008a). The consortium consisted of Arthrobacter sp. strain WY and Acinetobacter sp. strain FW, both isolated from soil contaminated with municipal waste (Dhapa, Kolkata). The dual culture completely assimilated $1 \mathrm{~g} / \mathrm{L}$ of BBP in aqueous solution within 44 days at $28^{\circ} \mathrm{C}$ with no appreciable accumulation of intermediate metabolites. When Tween 80 was added to the co-culture, BBP was completely assimilated within 20 days. Arthrobacter sp. strain WY was able to utilize BBP as the sole source of carbon and energy. The strain WY was also able to utilize MBuP, MBzP, phthalic acid, or protocatechuic acid as sole carbon sources but could not grow on benzyl alcohol or 1butanol. On the other hand, Acinetobacter sp. strain FW was able to utilize both of the side-chain alcohols for growth but could not use BBP, MBuP, MBzP, phthalic acid, or protocatechuic acid. The strain FW also utilized benzaldehyde, benzoic acid, catechol, butyraldehyde, and butyric acid as sole carbon sources. The analysis of the degradation pathway established that strain WY first hydrolyzed BBP to its monoesters and then further to phthalic acid, which was metabolized to protocatechuic acid, $\beta$-carboxy-cis,cis-muconate, and ultimately leading to the tricarboxylic acid (TCA) cycle. Spectrophotometric data showed that protocatechuic acid was degraded by orthocleavage dioxygenation. The strain FW played no role in the degradation of BBP but possessed catabolic enzymes essential for the assimilation of free alcohols. This activity was absent in the strain WY. Thus, the two strains were complementary regarding the assimilation of this xenobiotic compound. However, the degradation of BBP by the consortium was slow. The authors hypothesized that the cause was a very low surface hydrophobicity of the cells of strain WY, which negatively affected the partitioning of the hydrophobic substrate between medium and cells. Their hypothesis was corroborated by a considerable increase of the rate of BBP degradation when surfactants were added (Chatterjee and Dutta 2008a).

The second consortium was a co-culture of Gordonia sp. strain MTCC 4818 and Arthrobacter sp. WY (Chatterjee and Dutta 2008b). These two strains were previously reported to utilize BBP individually as a sole source of carbon and energy, but the individual strains could not completely degrade BBP (Chatterjee and Dutta 2003, 2008a). The limitations of the individual strains were overcome in dual culture, which completely mineralized BBP without identifiable intermediates within $108 \mathrm{~h}$. Analysis of esterases involved in the key initial metabolic steps of the BBP degradation pathway indicated the presence of multiple esterases in both species. The esterases were induced by BBP and possessed unique or broad substrate specificities toward BBP and its monoesters. The weak ability to hydrolyze monoesters and the inability to metabolize phthalic acid in Gordonia sp. were compensated for by the abilities of Arthrobacter sp. On the other hand, the inability to utilize BBP-hydrolyzed alcohols by Arthrobacter sp. was compensated for by Gordonia sp. Moreover, a number of catabolic enzymes other than esterases participated in the metabolism of BBP. The co-culture completely degraded BBP (at an initial concentration of $1 \mathrm{~g} / \mathrm{L}$ ) in $72 \mathrm{~h}$ while bacterial growth reached the stationary phase at $108 \mathrm{~h}$. During the growth period, very low concentrations of products of hydrolyzed BBP and other intermediate metabolites accumulated in the culture, indicating continuous utilization of intermediates during incubation. Although the co-culture started with equal numbers of both bacteria, the ratio of the Gordonia to Arthrobacter cells was higher during the initial hours of degradation relative to the later stages, indicating the ability of the 
former strain to metabolize BBP more rapidly and to utilize the hydrolyzed alcohols for growth (Chatterjee and Dutta 2008b).

To understand the involvement of esterase(s) in the degradation of BBP by the co-culture, Chatterjee and Dutta (2008b) determined the production of hydrolytic enzymes in Gordonia sp. strain MTCC 4818 and Arthrobacter sp. strain WY. Activity profiles of the esterases indicated that the BBP-hydrolyzing activities of the two bacteria were similar but that monoester-hydrolyzing activity was much higher in the cell-free extract of BBP-grown cells of Arthrobacter sp. strain WY. Apart from degradation of BBP, this co-culture was able to completely degrade a mixture of phthalates of environmental concern.

A third example of a dual culture performing better than its constituents was reported by Chang et al. (2004). Strains of Corynebacterium sp. and Sphingomonas sp. were more effective when used as a dual culture than as single cultures for phthalates degradation. The mixed culture efficiently degraded eight phthalates, including BBP. The authors hypothesized that the higher efficiency of dual cultures resulted from synergistic effects of enzymes produced by each strain.

\section{Degradation in wastewater treatment processes}

A major environmental source of phthalates is water released from industrial and municipal wastewater treatment plants (WWTP). Municipal wastewater contains high concentrations (milligrams per liter) of phthalates due to urban runoff and discharges from households (Vikelsøe et al. 1998). Dioctyl phthalate, dimethyl phthalate (DMP), DBP, BBP, DEHP, and DINP are phthalates that are commonly found in municipal wastewater. Under most environmental conditions, abiotic hydrolysis of phthalates in wastewater is negligible (Staples et al. 1997). The poor mineralization property of phthalates in the wastewater treatment processes is due to their high hydrophobicity and low solubility, which cause phthalates to be adsorbed to suspended organic matter and to be subsequently transferred to settled sludges (Gavala et al. 2003). Enzymatic cleavage and subsequent degradation by microorganisms in wastewater and activated sludge removes a significant fraction of phthalates entering activated sludge in WWTP (Fauser et al. 2003; Marttinen et al. 2003). A substantial portion of the phthalates is first adsorbed to sludge and then degraded. The fate of phthalates in WWTP and laboratoryscaled reactors has been well studied. Roslev et al. (2007) reported a BBP biodegradation rate of $0.726 \mathrm{~kg} /$ day at a WWTP in Aalborg, Denmark, and predicted that the anaerobic mesophilic digestion process and activated sludge process facilitated the main biodegradation activity, as was observed in other studies (Cheng et al. 2000; Gavala et al. 2003; Marttinen et al. 2003). About 90\% of BBP were biodegraded, and very low amounts of DBP and BBP entering Aalborg East WWTP were recovered in treated dewatered sludge in their experiment (Roslev et al. 2007). Although biodegradation removes much of the phthalate that enters activated sludge in WWTPs, the underlying biotic processes and abiotic conditions are poorly understood.

\section{Degradation by fungi}

Fungal degradation of phthalate esters, particularly aryl alkyl phthalates, has been less studied than bacterial degradation. The wide range of degradation abilities of fungi is due to the high activities of their extracellular ligninolytic enzymes, such as laccase, manganesedependent peroxidase, and lignin peroxidase. As an example, a fungal cutinase produced by Fusarium oxysporum f. sp. pisi strain showed high activities toward various phthalates (Ahn et al. 2006; Kim and Lee 2005; Kim et al. 2002, 2003, 2005, 2007). In the case of BBP, fungal cutinase ( $10 \mathrm{mg}$ protein/L) from $F$. oxysporum $\mathrm{f}$. $\mathrm{sp}$. pisi degraded almost $60 \%$ of the initial BBP $(500 \mathrm{mg} / \mathrm{L})$ within $7.5 \mathrm{~h}$ while yeast esterase $(10 \mathrm{mg}$ protein/L) from Candida cylindracea degraded less than $10 \%$ of the initial BBP after 3 days (Kim et al. 2002). Significant hydrolysis of BBP after 3 days exposure to the yeast esterase required $100 \mathrm{mg} / \mathrm{L}$ of the enzyme. The cutinase $(10 \mathrm{mg} / \mathrm{L})$ and esterase $(100 \mathrm{mg} / \mathrm{L})$ hydrolyzed $85 \%$ and $80 \%$, respectively, of $p$-nitrophenyl butyrate in a $0.1 \%$ methanol solution at $30^{\circ} \mathrm{C}$ during $72 \mathrm{~h}$. Stability of cutinase activity was greater than that of esterase within this period. The values of the degradation constants indicated that the initial rate of BBP degradation was more than four times greater with cutinase than with esterase and that more than $30 \%$ of the initial BBP was degraded by cutinase within the first $15 \mathrm{~min}$. The mechanism of the enzymatic decomposition was determined by identifying the following intermediates of degradation: butyl methyl phthalate (BMP), dimethyl phthalate (DMP), benzene methanol (BM), 1,3-isobenzofurandione (IBF), and an unidentified compound. Among them, IBF was a major metabolite produced during the initial $7.5 \mathrm{~h}$ in both enzymatic processes, and the concentration of IBF decreased thereafter. For the esterase, BMP was the most abundant product after 3 days. For the cutinase, degradation products other than IBF were produced at very low concentrations. The major product of degradation by the esterase, BMP, was found to be toxic and damaged the protein of the bacteria (recombinant bioluminescent Escherichia coli), whereas the other metabolites and the enzymes were not toxic (Kim et al. 2002).

Seok et al. (2008) recently investigated the biodegradation of the phthalates DEP, DMP, and BBP by ten white rot 
fungi isolated in Korea. The fungi were Pleurotus ostreatus, Irpex lacteus, Polyporus brumalis, Schizophyllum commune, Fomitella fraxinea, Merulius tremellosus, Trametes versicolor, and T. versicolor $\mathrm{MrP} 1, \mathrm{MrP} 13$ (transformant of the Mn-repressed peroxidase gene of $T$. versicolor) and MnP2-6 (transformant of the Mn-dependent peroxidase gene of $T$. versicolor). When fungal mycelia were added together with $100 \mathrm{mg} / \mathrm{L}$ of each phthalate to yeast extractmalt extract-glucose (YMG) medium, phthalate degradation occurred within 12 days. For all fungi but I. lacteus, growing the fungus for 5 days before addition of the phthalate resulted in greater degradation of the phthalates. For example, this pre-incubation increased the rate of BBP degradation 1.5 to 4 times. P. ostreatus degraded BBP most efficiently. The supernatant of a $P$. ostreatus culture, obtained by growing the fungus in YMG medium for 4 days at $30^{\circ} \mathrm{C}$, degraded only $14.9 \%$ of $100 \mathrm{mg} / \mathrm{L}$ BBP. Washed intact mycelia and homogenized mycelia degraded all BBP within 2 days even in distilled water, indicating that $P$. ostreatus degrades phthalates by intracellular or mycelium-associated enzymes. Indeed, enzymes responsible for the degradation of xenobiotics are often cell wall bound, like laccase of I. lacteus (Svobodová et al. 2006) or intracellular, like DMP-degrading esterase from Bacillus sp. (Niazi et al. 2001). Filamentous fungi like P. ostreatus can produce hydrophobins (Peñas et al. 2002), which are lowmolecular-weight proteins that can render the fungal structure hydrophobic (Linder et al. 2005) and may result in denser fungal pellets in aqueous media. The hydrophobic fungal structures readily adsorb hydrophobic phthalates and thereby facilitate degradation.

Figure 3a compares the degradation of BBP by fungi. For a comparison, hydrolysis of BBP by cutinase $(10 \mathrm{mg}$ protein/L) from F. oxysporum f. sp. pisi was included, which removed $300 \mathrm{mg} / \mathrm{L}$ of BBP within $7.5 \mathrm{~h}$. Other ten white rot fungi degraded 80 to $100 \mathrm{mg} / \mathrm{L}$ of BBP within 6 to 12 days. Among these, P. brumalis, T. versicolor, and the transformants of $T$. versicolor, MrP1 and MnP2-6, degraded $100 \mathrm{mg} / \mathrm{L}$ of BBP much faster than the other strains tested. T. versicolor has high lignin-degrading activity and the ligninolytic enzymes, such as Mn-repressed peroxidase or Mn-dependent peroxidase is responsible for the degradation of recalcitrant compounds (Seok et al. 2008; Yeo et al. 2007). Therefore, overexpressed genes of these enzymes facilitated the degradation rate in case of $T$. versicolor transformants. Other transformant $\mathrm{MrP} 13$ can degrade $95 \mathrm{mg} / \mathrm{L}$ of BBP but took longer time (12 days), and authors speculated that lower growth rates of the transformant was the responsible factor for this result (Seok et al. 2008). Strain S. commune was poorest BBP degrader among these ten white rot fungi and can degrade only $80.3 \mathrm{mg} / \mathrm{L}$ of BBP in 12 days. Figure $3 \mathrm{~b}$ compared the BBP degradation efficiency among ten
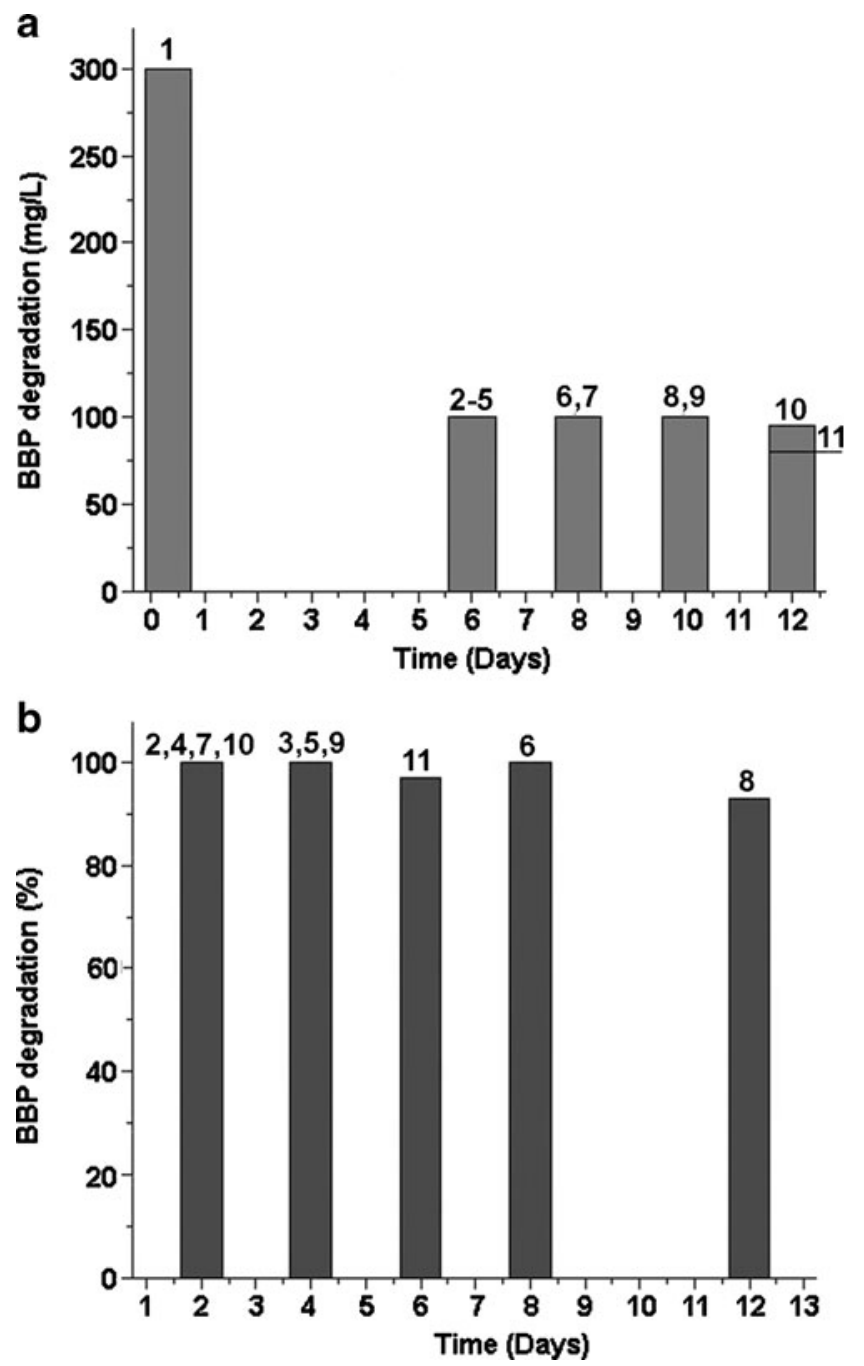

Fig. 3 Degradation of BBP by fungi. a BBP was incubated with (1) F. oxysporum $\mathrm{f}$. sp. pisi cutinase $(10 \mathrm{mg}$ protein/L) in Tris- $\mathrm{HCl}$ buffer (10 mM, pH8.0) (Kim et al. 2002); (2) P. brumalis; (3) T. versicolor; (4) T. versicolor MrP1; (5) T. versicolor MnP2-6; (6) F. fraxinea; (7) P. ostreatus; (8) I. lacteus; (9) M. tremellosus; (10) T. versicolor $\mathrm{MrP13}$; (11) S. commune were incubated with BBP in YMG medium (Seok et al. 2008) using 10\% (w/v) fungal mycelium as inoculum. Initial concentration of BBP was $500 \mathrm{mg} / \mathrm{L}$ for (1) and $100 \mathrm{mg} / \mathrm{L}$ for (2-11). The standard deviation was negligibly small for (1), zero for (2-9), $2.7 \%$ for (10), and $0.3 \%$ for (11). b BBP was added into 5-dayold fungal cultures grown in YMG medium. Standard deviation for strains $(8)$ and $(11)$ were $2.8 \%$ and $4.2 \%$, respectively. For the other strains, the standard deviation values were negligibly small. Initial concentration of $\mathrm{BBP}$ was $100 \mathrm{mg} / \mathrm{L}$

white rot fungi grown separately in YMG medium for 5 days before addition of BBP. In this condition, $P$. brumalis, $P$. ostreatus, and transformants of $T$. versicolor, $\mathrm{MrP} 1$ and $\mathrm{MrP} 13$, showed higher degradation rate. Among these ten strains, I. lacteus was the slowest degrader in this condition which can degrade $92.7 \mathrm{mg} / \mathrm{L}$ of BBP in 12 days. 
Sonochemical degradation

Ultrasound can enhance oxidation and has recently received increasing attention for the treatment of chemical contaminants in water. Ultrasonic irradiation of aqueous solutions induces acoustic cavitation, which concentrates the diffuse energy of ultrasound into micro-reactors. In the context of sonochemical degradation, cavitation is defined as the cyclic formation, growth, and subsequent collapse of microbubbles or cavities; this cavitation occurs in extremely small intervals of time and releases large quantities of energy over a small location (Gogate 2002). The heat generated during cavity implosion decomposes water into free hydrogen atoms and hydroxyl radicals, which are both extremely reactive. During the cooling phase, the atoms and radicals recombine to form hydrogen peroxide and molecular hydrogen (Ince et al. 2001). This environment enhances the decomposition of organic compounds and the oxidation or reduction of inorganic complexes (Seymour and Gupta 1997). Hydrophobic solutes are particularly prone to degradation by low-frequency ultrasonic cavitation because they accumulate at the water-gas interface and are directly exposed to hydroxylation and thermal decomposition when the bubble collapses (Ince et al. 2001). Successful removal of a wide range of organic pollutants from aqueous solution by ultrasound treatment indicates that sonochemical degradation could be widely used for environmental remediation (Adewuyi 2001).

Psillakis et al. (2004) reported the sonochemical degradation of aqueous solutions of six phthalates at very low concentrations (microgram per liter); the experiments used continuous ultrasonic irradiation (frequency of $80 \mathrm{kHz}$ ) at a constant electric power output of $150 \mathrm{~W}$ and a constant water bath temperature of $21^{\circ} \mathrm{C}$. Starting with $40 \mu \mathrm{g} / \mathrm{L}$ of BBP (initial overall concentration of phthalates was $240 \mu \mathrm{g} / \mathrm{L}$ ), the authors found that almost $97 \%$ of BBP was degraded within $60 \mathrm{~min}$ and that no BBP was detected after $120 \mathrm{~min}$. The presence of $10 \%(w / v) \mathrm{NaCl}$ enhanced the removal rates for the more polar phthalates, DMP, DEP, BBP, and DBP. In the presence of $\mathrm{NaCl}$, solubility of phthalates in the reaction mixture decreased, and diffusion of solutes from the bulk solution to the bubble-water interface was enhanced. This facilitated solute accumulation in the interfacial sheath, resulting in their faster degradation; only a trace quantity of phthalic acid was detected as a degradation product (Psillakis et al. 2004).

\section{Degradation in landfills}

Phthalates are weakly bound to plastics and therefore readily leach from plastic products into the environment. Appreciable amounts of phthalates have been detected in liquid samples withdrawn from landfills (Oman and
Hynning 1993) and in landfill leachates (Bauer et al. 1998; Jonsson et al. 2003a).

Mineralization of organic compounds in landfills is mostly anaerobic and occurs in three phases. After the first two phases of hydrolysis and fermentation, organic substrates are converted into a series of intermediates including fatty acids and alcohols, which finally lead to hydrogen, methane, and carbon dioxide (Christensen and Kjeldsen 1989). Phthalate diesters in landfills are degraded by methanogenic consortia, which release phthalate monoesters into the leachate in the first phase of the degradation. The degradation of BBP and DEHP was confirmed experimentally (Jonsson et al. 2003b). The anaerobic phthalate biodegradation in landfills, however, is less efficient than the degradation in anaerobic reactors (Ejlertsson et al. 1996).

\section{Photocatalytic degradation}

Xu et al. (2009) recently described photocatalytic degradation of BBP using UV light in the presence of the photocatalyst $\mathrm{TiO}_{2}$. At neutral $\mathrm{pH}, \mathrm{BBP}$ was adsorbed on $\mathrm{TiO}_{2}$ particles because of zero charge density (isoelectric point of the catalyst about $\mathrm{pH} 6.2-7.5$ ) of the catalyst. Irradiation (at $350 \mathrm{~nm}$ for $2 \mathrm{~h})$ of an aqueous solution containing $\mathrm{TiO}_{2}(2 \mathrm{~g} / \mathrm{L})$ degraded nearly $0.8 \mathrm{mg} / \mathrm{L}$ of BBP and the process followed pseudofirst-order kinetics. Increasing the concentration of $\mathrm{TiO}_{2}$ up to $2 \mathrm{~g} / \mathrm{L}$ increased the degradation rate because it increased the total surface area of the catalyst. A higher concentration of the catalyst $(>2 \mathrm{~g} / \mathrm{L})$ does not enhance degradation because it decreases light penetration, increases light scattering, and may limit access to the catalyst surface due to catalyst agglomeration. The authors showed that addition of electron acceptors such as $\mathrm{BrO}_{3}^{-}, \mathrm{ClO}_{4}^{-}$, and $\mathrm{Cr}_{2} \mathrm{O}_{7}{ }^{2-}$ enhanced BBP degradation. This may be due to the withdrawal of free electrons by these radical anions, which restrict the recombination of electrons and holes (the activity of semiconductor photocatalysts is determined by free electron-hole pairs, generated when semiconductor particles are illuminated with light of the energy larger than the semiconductor band gap (Xu et al. 2009)). On the other hand, the addition of cations $\mathrm{K}^{+}$, $\mathrm{Na}^{+}, \mathrm{Mg}^{2+}, \mathrm{Ca}^{2+}$ and anions $\mathrm{PO}_{4}{ }^{3-}, \mathrm{CO}_{3}{ }^{2-}, \mathrm{NO}_{3}{ }^{-}, \mathrm{SO}_{4}{ }^{3-}$, $\mathrm{Cl}^{-}$slowed BBP degradation. These ions were adsorbed on the surface of $\mathrm{TiO}_{2}$ and blocked its active sites. Scavenging of hydroxyl radicals by phosphate and carbonate also contributed to the reduction of the degradation rate. Addition of acetone or methanol to $0.01 \mathrm{M}$ decreased the efficiency of photocatalytic degradation, probably because these small molecules blocked the active sites, scavenging hydroxyl radicals. Similar to the bacterial degradation of BBP, the major intermediates of photocatalytic degradation were $\mathrm{MBuP}, \mathrm{MBz}$, and phthalic acid (Xu et al. 2009). 


\section{Biodegradation pathway}

Mineralization of phthalic acid ester in the environment is largely microbial and involves a sequence of reactions that is common to all phthalates (Hashizume et al. 2002; Staples et al. 1997; Yuan et al. 2002). At first, the ester linkage between alkyl chains and the aromatic ring is hydrolyzed to form monoesters and then phthalic acid (Ribbons et al. 1984; Wang et al. 1999), which is oxidized via the 3-oxoadipate pathway (Engelhardt et al. 1976; Ribbons and Evans 1960). In the case of BBP, the same course of degradation, with monoesters as intermediates, was reported for different microorganisms (Chatterjee and Dutta 2003, 2008a; Xu et al. 2006). Phthalic acid is converted to protocatechuic acid, which degrades to ß-carboxy-cis,cismuconate via the ortho-cleavage pathway (Fig. 4) and is immediately transformed into $\gamma$-carboxy muconolactone leading to the TCA cycle (Chatterjee and Dutta 2008a).

Selective hydrolysis of one ester bond leading to monoalkyl phthalate and alcohol has also been reported; alcohols supported the growth of the microorganisms in these cases (Kurane 1986; Roslev et al. 1998). Benzoate was degraded via catechol, which was further cleaved by the action of catechol 1,2-dioxygenase (Neidle and Ornston 1987; Ngai et al. 1990; Ornston 1966). The BBP hydrolysis products benzyl alcohol and butanol were degraded sequentially, and the products were fed into the TCA cycle (Fig. 4). Benzyl alcohol was converted to benzaldehyde by the action of benzyl alcohol dehydrogenase and further to benzoic acid by benzaldehyde dehydrogenase. These transformation processes were $\mathrm{NAD}^{+}$dependent. Although direct biotransformation products of benzoic acid have not been identified, catechol was identified as one of the intermediates of benzoic acid catabolism by Gordonia sp. strain 4818 (Chatterjee et al. 2005). In the presence of NADH, however, the cell-free extract can transform benzoic acid and possibly the so-farundetected intermediate product cis-1,6-dihydroxy-2,4 cyclohexadiene-1-carboxylic acid, which is formed from benzoic acid, into catechol. Catechol was then degraded by catechol 1,2-dioxygenase following the ortho-cleavage pathway to form cis,cis-muconic acid. Cis,cis-muconic acid was transformed into muconolactone and ultimately entered the TCA cycle. On the other hand, butanol degradation followed the $\beta$-oxidation pathway after being transformed into butyric acid via butyraldehyde. The transformation of butanol to butyraldehyde and butyric acid by dehydrogenases was assumed to be $\mathrm{NAD}^{+}$ dependent (Chatterjee et al. 2005). Degradation of BBP by co-cultures followed the same pathway as degradation by single cultures (Chatterjee and Dutta 2008a, b). Xu et al. (2006) described the degradation pathway of BBP by $P$. fluorescens B-1. The strain first cleaved the ester bonds of the diester to yield phthalate monoesters. Then monoesters were degraded to form phthalic acid, which after decarboxylation, was converted to benzoic acid. Benzoic acid was further metabolized to produce carbon dioxide and water, but these latter steps have not been elucidated in detail.

Fungal degradation of BBP differs from bacterial degradation of BBP. BBP degradation by fungal cutinase (F. oxysporum f. sp. pisi) and yeast esterase (C. cylindracea) produces IBF via ester hydrolysis, followed by spontaneous oxo bridge formation (Kim et al. 2002). IBF is then converted to BMP and DMP via transesterification of esterase and cutinase (separately) in $0.1 \%$ methanol. Another compound, benzene methanol, was found as an ester hydrolysis product of BBP. The composition of conversion products of IBF depends on the enzymes involved. The relative amounts of products of BBP degradation generated by the hydrolytic enzymes cutinase and esterase differed. Cutinase degradation mainly produced an unidentified compound while esterase degradation mainly produced BMP. Methyl and butyl esters in BMP and DMP found among the reaction products were thought to originate from the esterification of one of the hydrolysis products of BBP by methanol (Kim et al. 2002) (Fig. 4).

In the photocatalytic degradation pathway, BBP was first converted into a radical anion and then formed an anionic species with the addition of a hydroxyl radical in the corresponding carbon atom. This species then becomes protonated and loses a butanol or benzyl alcohol from the BBP moiety, forming MBuP and MBzP. Monoesters are then transformed to produce phthalic acid by the action of electrons and hydroxyl radicals. Phthalic acid is finally mineralized to $\mathrm{CO}_{2}$ and water (Xu et al. 2009).

\section{Future research on BBP biodegradation}

The catabolic ability of microorganisms used in bioremediation can be enhanced by genetic engineering. With genetic engineering, researchers can generate novel degradation pathways by assembling catabolic modules of different origins in the same host cell. Recombinant organisms potentially allow the expansion of the specificity of degradation pathway to new substrates, completion of incomplete pathways, or even creation of new pathways not represented in nature. Bacteria or fungi harboring multiple catabolic pathways can be constructed. Rational combination and extension of natural catabolic pathways by genetic engineering may allow the degradation of recalcitrant xenobiotics and prevent the formation of dead-end products. However, undesirable non-target effects must be excluded before such organisms are 


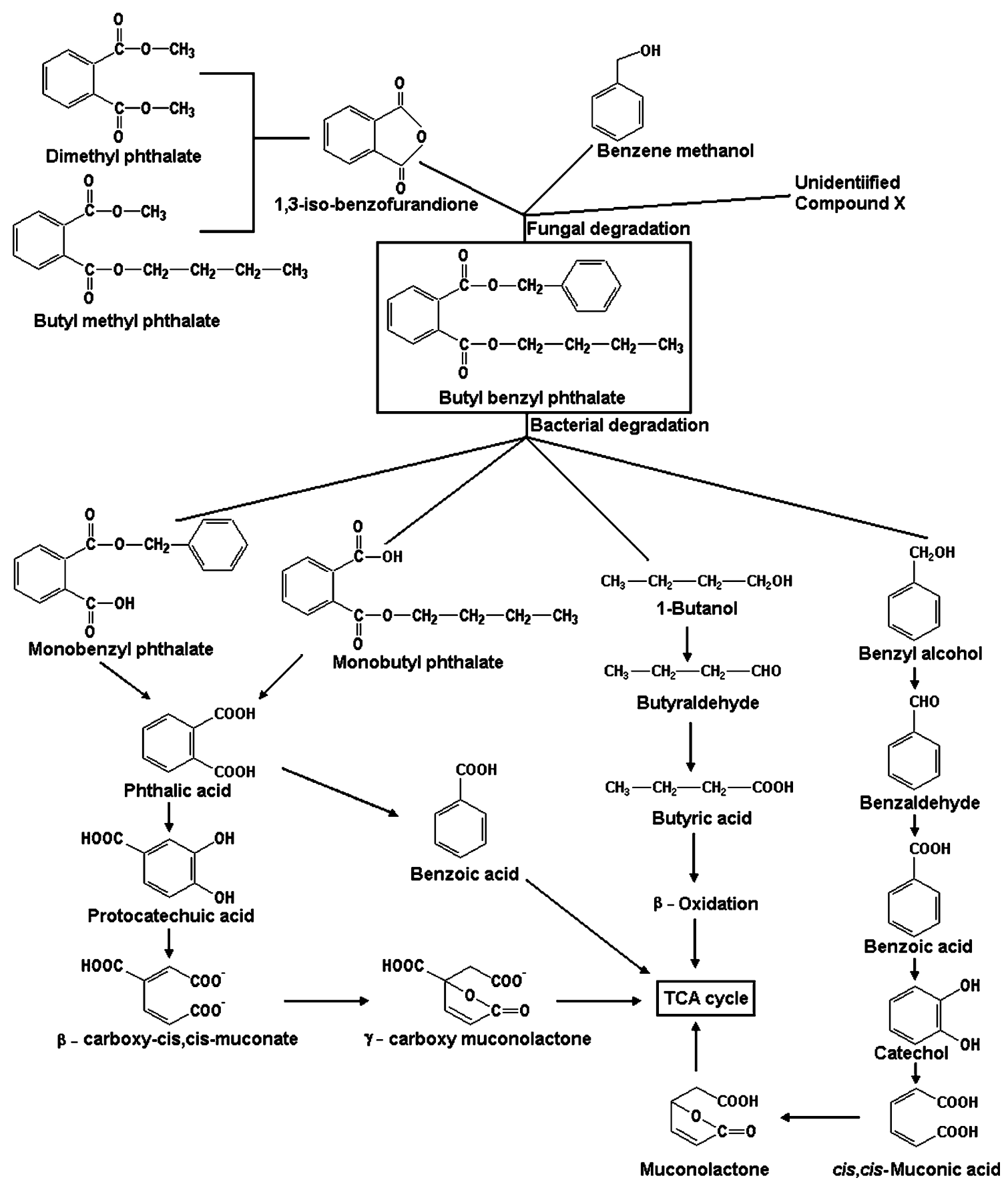

Fig. 4 Fungal and bacterial pathways for BBP degradation

released into the environment. Evolution of natural catabolic capabilities proceeds much slower than the speed with which new xenobiotics are being developed and introduced into the environment. Furthermore, the direction of selection pressure exerted by xenobiotics on natural microorganisms is not necessarily congruent with the demands of bioremediation. For example, xenobiotics that are toxic to microorgan- isms and/or that yield a low amount of net energy are less likely to become the target of new pathways than nontoxic, high-energy yielding xenobiotics, irrespective of their relevance for the health of humans and animals. We therefore expect that catabolic pathways designed by humans will be instrumental in the removal of toxic man-made chemicals like BBP from the environment in future. 
Open Access This article is distributed under the terms of the Creative Commons Attribution Noncommercial License which permits any noncommercial use, distribution, and reproduction in any medium, provided the original author(s) and source are credited.

\section{References}

Adewuyi YG (2001) Sonochemistry: environmental science and engineering applications. Ind Eng Chem Res 40:4681-4715

Agas D, Sabbieti MG, Capacchietti M, Materazzi S, Menghi G, Materazzi G, Hurley MM, Marchetti L (2007) Benzyl butyl phthalate influences actin distribution and cell proliferation in rat py1a osteoblasts. J Cellular Biochemistry 101:543-551

Ahn JY, Kim YH, Min J, Lee J (2006) Accelerated degradation of dipentyl phthalate by Fusarium oxysporum f. sp pisi cutinase and toxicity evaluation of its degradation products using bioluminescent bacteria. Curr Microbiol 52:340-344

ATSDR (1995) Toxicological profile for diethyl phthalate. Atlanta, GA: Agency for Toxic Substances and Disease Registry. Available: http://www.atsdr.cdc.gov/toxprofiles/tp73.html

ATSDR (2000) Toxicological profile for di (2-ethylhexyl) phthalate. Atlanta, GA: Agency for Toxic Substances and Disease Registry. Available: http://www.atsdr.cdc.gov/toxprofiles.html

Bauer MJ, Herrmann R (1997) Estimation of the environmental contamination by phthalic acid esters leaching from household wastes. Sci Total Environ 208:49-57

Bauer MJ, Herrmann R, Martin A, Zellmann H (1998) Chemodynamics, transport, behavior and treatment of phthalic acid esters in municipal landfill leachates. Water Sci Technol 38:185-192

Blount BC, Milgram KE, Silva MJ, Malek NA, Reidy JA, Needham LL, Brock JW (2000a) Quantitative detection of eight phthalate metabolites in human urine using HPLC-APCIMS/ MS. Anal Chem 72:4127-4134

Blount BC, Silva MJ, Caudill SP, Needham LL, Pirkle JL, Sampson EJ, Lucier GW, Jackson RJ, Brock JW (2000b) Levels of seven urinary phthalate metabolites in a human reference population. Environ Health Perspect 108:972-982

Bornehag CG, Sundell J, Weschler CJ, Sigsgaard T, Lundgren B, Hasselgren M, Hagerhed-Engman L (2004) The association between asthma and allergic symptoms in children and phthalates in house dust: a nested case-control study. Environ Health Perspect 112:1393-1397

Carlsen E, Giwercman A, Keiding N, Skakkebaek NE (1992) Evidence for decreasing quality of semen during past 50 years. Br Med J 305:609-613

Center for the Evaluation of Risks to Human Reproduction (CERHR) (2000) NTP CERHR expert panel report on di(2-ethylhexyl) phthalate. Science International, Inc., Alexandria, VA

Chang BV, Wang TH, Yuan SY (2007) Biodegradation of four phthalate esters in sludge. Chemosphere 69:1116-1123

Chang BV, Shiung LS, Yuan SY (2002) Anaerobic degradation of polycyclic aromatic hydrocarbons in soil. Chemosphere 48:717-724

Chang BV, Yang CM, Cheng CH, Yuan SY (2004) Biodegradation of phthalate esters by two bacteria strains. Chemosphere 55:533538

Chatterjee S, Dutta TK (2003) Metabolism of butyl benzyl phthalate by Gordonia sp. strain MTCC 4818. Biochem Biophys Res Commun 309:36-43

Chatterjee S, Dutta TK (2008a) Complete degradation of butyl benzyl phthalate by a defined bacterial consortium: role of individual isolates in the assimilation pathway. Chemosphere 70:933-941

Chatterjee S, Mallick S, Dutta TK (2005) Pathways in the degradation of hydrolyzed alcohols of butyl benzyl phthalate in metabolically diverse Gordonia sp. strain MTCC 4818. J Mol Microbiol Biotechnol 9:110-120

Chatterjee S, Dutta TK (2008b) Metabolic cooperation of Gordonia sp. strain MTCC 4818 and Arthrobacter sp. strain WY in the utilization of butyl benzyl phthalate: effect of a novel coculture in the degradation of mixture of phthalates. Microbiology 154:33383346

Cheng HF, Chen SY, Lin JG (2000) Biodegradation of di-(2-ethylhexyl) phthalate in sewage sludge. Water Sci Technol 41:1-6

Christensen TH, Kjeldsen P (1989) Basic biochemical processes in landfills. In: Christensen TH, Cossu R, Stegmann R (eds) Sanitary landfilling: process, technology and environmental impact. Academic Press, London, pp 29-49

CICAD (1999) Concise international chemical assessment documents 17 , on butyl benzyl phthalate. WHO, Geneva.

CMA (1999) Comments of the chemical manufacturers association phthalate esters panel in response to request for public input on seven phthalate esters. FR Doc. 99-9484. Washington, DC: Chemical Manufacturers Association.

Dyer CA (2007) Heavy metals as endocrine disrupting chemicals, endocrine disrupting chemicals: from basic research to clinical practice. Humana Press Inc, Totowa, NJ, pp 111-133, Chapter 5

Ejlertsson J, Houwen FP, Svensson BH (1996) Anaerobic degradation of diethyl phthalate and phthalic acid during incubation of municipal solid waste from a biogas digester. Swed J Agric Res 26:53-59

Ema M, Miyawaki E, Hirose A, Kamata E (2003) Decreased anogenital distance and increased incidence of undescended testes in fetuses of rats given monobenzyl phthalate, a major metabolite of butyl benzyl phthalate. Reprod Toxicol 17:407-412

Ema M, Miyawaki E (2002) Effects on development of the reproductive system in male offspring of rats given butyl benzyl phthalate during late pregnancy. Reprod Toxicol 16:71-76

Ema M, Miyawaki E, Kawashima K (1999) Developmental effects of plasticizers butyl benzyl phthalate after a single administration in rats. J Appl Toxicol 19:357-365

Engelhardt G, Wallnofer PR, Rast HG, Fiedler (1976) Metabolism of $o$-phthalic acid by different gram-negative and gram-positive soil bacteria. Arch Microbiol 109:109-114

Fauser P, Vikelsøe J, Sørensen PB, Carlsen L (2003) Phthalates, nonylphenols and LAS in an alternately operated wastewater treatment plant-fate modelling based on measured concentrations in wastewater and sludge. Water Res 37:1288-1295

Gavala HN, Alatriste-Mondragon F, Iranpour R, Ahring BK (2003) Biodegradation of phthalate esters during the mesophilic anaerobic digestion of sludge. Chemosphere 52:673-682

Giam CS, Atlas E, Powers MA Jr, Leonard JE (1984) Phthalic acid esters. In: Hutzinger O (ed) Handbook of environmental chemistry, Part C, vol 3, Springer-Verlag. New York, Berlin, pp 67-140

Gilbert SF (2006) Developmental biology, Eighth Edition, Sinauer Associate Inc., Chapter 21

Gogate PR (2002) Cavitation: an auxiliary technique in wastewater treatment schemes. Adv Environ Res 6:335-358

Graedel TE, Hawkins DT, Claxton LD (1986) Atmospheric chemical compounds: sources, occurrence, and bioassay. Academic Press, Inc., Harcourt Brace Jovanovich Publishers, New York, NY

Gray LE Jr, Ostby J, Furr J, Price M, Veeramachaneni DN, Parks L (2000) Perinatal exposure to the phthalates DEHP, BBP, and DINP, but not DEP, DMP, or DOTP, alters sexual differentiation of the male rat. Toxicol Sci 58:350-365

Harris CA, Henttu P, Parker MG, Sumpter JP (1997) The estrogenic activity of phthalate esters in vitro. Environ Health Perspect 105:802-811

Hashizume K, Nanya J, Toda C, Yasui T, Nagano H, Kojima N (2002) Phthalate esters detected in various water samples and biodegradation of the phthalates by microbes isolated from river water. Biol Pharm Bull 25:209-214 
Hewitt R, Forero A, Luncsford PJ, Martin FL (2007) Enhanced micronucleus formation and modulation of BCL-2: BAX in MCF-7 cells after exposure to binary mixtures. Environ Health Perspect 115(Suppl 1):129-136

Ince NH, Tezcanli G, Belen RK, Apikyan IG (2001) Ultrasound as a catalyzer of aqueous reaction systems: the state of the art and environmental applications. Appl Catal B: Environ 29:167-176

IPCS (1999) Concise international chemical assessment document 17, butyl benzyl phthalate. WHO, Geneva, International Programme on Chemical Safety.

Jiao H, Allinson SL, Walsh MJ, Hewitt R, Cole KJ, Phillips DH, Martin FL (2007) Growth kinetics in MCF-7 cells modulate benzo[a]pyrene-induced CYP1A1 up-regulation. Mutagenesis 22:111-116

Jobling S, Reynolds T, White R, Parker MG, Sumpter JP (1995) A variety of environmentally persistent chemicals, including some phthalates plasticizers are weakly estrogenic. Environ Health Perspect 103:582-587

Jonsson S, Ejlertsson J, Ledin A, Mersiowsky I, Svensson BH (2003a) Mono- and diesters from o-phthalic acid in leachates from different European landfills. Water Res 37:609-617

Jonsson S, Ejlertsson J, Svensson BH (2003b) Transformation of phthalates in young landfill cells. Waste Manag 23:641-651

Kang SC, Lee BM (2005) DNA methylation of estrogen receptor alpha gene by phthalates. J Toxicol Environ Health A 68:1995-2003

Kato K, Silva MJ, Brock JW, Reidy JA, Malek NA, Hodge CC, Nakazawa H, Needham LL, Barr DB (2003) Quantitative detection of nine phthalate metabolites in human serum using reversed-phase high-performance liquid chromatography-electrospray ionization-tandem mass spectrometry. J Anal Toxicol 27:284-289

Kim YH, Lee J (2005) Enzymatic degradation of dibutyl phthalate and toxicity of its degradation products. Biotechnol Lett 27:635-639

Kim YH, Lee J, Moon SH (2003) Degradation of an endocrine disrupting chemical, DEHP [di-(2-ethylhexyl)-phthalate], by Fusarium oxysporum f. sp pisi cutinase. Appl Microbiol Biotechnol 63:75-80

Kim YH, Lee JW, Ahn JY, Gu MB, Moon SH (2002) Enhanced degradation of an endocrine-disrupting chemical, butyl benzyl phthalate, by Fusarium oxysporum f. sp pisi cutinase. Appl Environ Microbiol 68:4684-4688

Kim YH, Min JH, Bae KD, Gu MB, Lee J (2005) Biodegradation of dipropyl phthalate and toxicity of its degradation products: a comparison of Fusarium oxysporum f. sp pisi cutinase and Candida cylindracea esterase. Arch Microbiol 184:25-31

Kim YH, Seo HS, Min J, Kim YC, Ban YH, Han KY, Park JS, Bae $\mathrm{KD}, \mathrm{Gu} \mathrm{MB}$, Lee J (2007) Enhanced degradation and toxicity reduction of dihexyl phthalate by Fusarium oxysporum f. sp pisi cutinase. J Appl Microbiol 102:221-228

Kurane R (1986) Microbial degradation of phthalate esters. Microbiol Sci 3:92-95

Lertsirisopon R, Soda S, Sei K, Ike M, Fujita M (2006) Biodegradability of four phthalic acid esters under anaerobic condition assessed using natural sediment. J Environ Sci (China) 18:793-796

Li WL, Yang YN, Ji YB, Yu L, Fan YQ (2005) Biodegradation of butylbenzyl phthalate by acclimated activated sludge. Huan Jing Ke Xue (Chinese) 26:156-159

Linder MB, Szilvay GR, Nakari-Setälä T, Penttilä ME (2005) Hydrophobins: the protein-amphiphiles of filamentous fungi. FEMS Microbiol Rev 29:877-896

Liu PS, Chen YY (2006) Butyl benzyl phthalate blocks $\mathrm{Ca}^{2+}$ signaling coupled with purinoceptor in rat $\mathrm{PC} 12$ cells. Toxicol Appl Pharmacol 210:136-141
Liu Y, Guan Y, Yang Z, Cai Z, Mizuno T, Tsuno H, Zhu W, Zhang X (2009) Toxicity of seven phthalate esters to embryonic development of the abalone Haliotis diversicolor supertexta. Ecotoxicology 18:293-303

Marttinen SK, Kettunen RH, Sormunen KM, Rintala JA (2003) Removal of bis(2-ethylhexyl) phthalate at a sewage treatment plant. Water Res 37:1385-1393

Moral R, Wang R, Russo IH, Mailo DA, Lamartiniere CA, Russo J (2007) The plasticizer butyl benzyl phthalate induces genomic changes in rat mammary gland after neonatal/prepubertal exposure. BMC Genomics 8:453

Nagao T, Ohta R, Marumo H, Shindo T, Yoshimura S, Ono H (2000) Effect of butyl benzyl phthalate in Sprague-Dawley rats after gavage administration: a two-generation reproductive study. Reprod Toxicol 14:513-532

Nakai M, Tabira Y, Asai D, Yakabe Y, Shimyozu T, Noguchi M, Takatsuki M, Shimohigashi Y (1999) Binding characteristics of dialkyl phthalates for the estrogen receptor. Biochem Biophys Res Commun 254:311-314

Nativelle C, Picard K, Valentin I, Lhuguenot JC, Chagon MC (1999) Metabolism of $n$-butyl benzyl phthalate in Wistar female rat. Identification of new metabolites. Food Chem Toxicol 37:905-917

Neidle EL, Ornston LN (1987) Benzoate and muconate, structurally dissimilar metabolites, induce expression of catA in Acinetobacter calcoaceticus. J Bacteriol 169:414-415

Ngai KL, Neidle EL, Ornstorn LN (1990) Catechol and chlorocatechol 1, 2-dioxygenase. Methods Enzymol 188:122-126

Niazi JH, Prasad DT, Karegoudar TB (2001) Initial degradation of dimethylphthalate by esterases from Bacillus species. FEMS Microbiol Lett 196:201-205

NTP: NTP-CERHR Monograph on the Potential Human Reproductive and Developmental Effects of Butyl Benzyl Phthalate (BBP). NTP CERHR MON (2003):i-III90.

Oman C, Hynning PA (1993) Identification of organic compounds in municipal solid landfill leachates. Environ Pollut 80:265-271

Oppelt ET (1987) Incineration of hazard waste. A critical review. J Air Pollut Control Assoc 37:558-586

Ornston LN (1966) The conversion of catechol and protocatechuate to ß-ketoadipate by Pseudomonas putida. IV. Regulation. J Biol Chem 241:3800-3810

Park KS, Sims RC, Dupont R (1990) Transformation of PAHs in soil systems. J Environ Eng (ASCE) 116:623-640

Peñas MM, Luis BR, Larray M, Ramírez L, Pisabarro AG (2002) Differentially regulated, vegetative-mycelium specific hydrophobins of the edible basidiomycete Pleurotus ostreatus. Appl Environ Microbiol 68:3891-3898

Picard K, Lhuguenot JC, Lavier-Canivenc MC, Chagnon MC (2001) Estrogenic activity and metabolism of $n$-butyl benzyl phthalate in vitro: identification of the active molecule(s). Toxicol Appl Pharmacol 172:108-118

Piersma AH, Verhoef A, Biesebeek JD, Pieters MN, Slob W (2000) Developmental toxicity of butyl benzyl phthalate in the rat using a multiple dose study design. Reprod Toxicol 14:417-425

Psillakis E, Mantzavinos D, Kalogerakis N (2004) Monitoring the sonochemical degradation of phthalate esters in water using solid-phase microextraction. Chemosphere 54:849-857

Reddy B, Rozati R, Reddy B, Raman N (2006) Association of phthalate esters with endometriosis in Indian women. BJOG 113:515-520

Ribbons DW, Evans WC (1960) Oxidative metabolism of phthalic acid by soil pseudomonads. Biochem J 76:310-318

Ribbons DW, Keyser P, Kunz DA, Taylor BF, Eaton RW, Anderson BN (1984) Microbial degradation of phthalates. In: Gibson DT (ed) Microbial degradation of organic compounds. Marcel Dekker, New York, pp 371-397 
Ritsema R, Cofino WP, Frintrop PCM, Brinkman UAT (1989) Tracelevel analysis of phthalate esters in surface water and suspended particulate matter by means of capillary gas chromatography with electron-capture and mass-selective detection. Chemosphere 18:2161-2175

Roslev P, Vorkamp K, Aarup J, Frederiksen K, Nielsen PH (2007) Degradation of phthalate esters in an activated sludge wastewater treatment plant. Water Res 41:969-976

Roslev P, Madsen PL, Thyme JB, Henriksen K (1998) Degradation of phthalate and di (2-ethylhexyl) phthalate by indigenous and inoculated microorganisms in sludge-amended soil. Appl Environ Microbiol 64:4711-4719

Saeger VW, Tucker ES (1976) Biodegradation of phthalic acid esters in river water and activated sludge. Appl Environ Microbiol 31:29-34

Safe S (2004) Endocrine disruptors and human health: is there a problem? Toxicology 205:3-10

Santharam SK, Erickson LE, Fan LT (1997) Modelling the role of surfactant and biodegradation in the remediation of aquifers with nonaqueous phase contaminants. J Hazard Mater 53:115-139

Seok HS, Choi HT, Song HG (2008) Biodegradation of endocrinedisrupting phthalates by Pleurotus ostreatus. J Microbiol Biotechnol 18:767-772

Seymour JD, Gupta RB (1997) Oxidation of aqueous pollutants using ultrasound: salt induced enhancement. Ind Eng Chem Res 36:3453-3457

Soto AM, Sonnenschein C, Chung KL, Fernandez MF, Olea N, Serrano FO (1995) The E-screen assay as a tool to identify estrogens: an update on estrogenic environmental pollutants. Environ Health Perspect 103:113-122

Staples CA, Peterson DR, Parkerton TF, Adams WJ (1997) The environmental fate of phthalate esters: a literature review. Chemosphere 35:667-749

Suslick KS, Hammerton DA, Cline RE Jr (1986) The sonochemical hot spot. J Am Chem Soc 108:5641-5642

Svobodová K, Majcherczyk A, Novotny È, Kües U (2006) Implication of mycelium-associated laccase from I. lacteus in the decolorization of synthetic dyes. Bioresour Technol 99:463-471
Swan SH (2008) Environmental phthalate exposure in relation to reproductive outcomes and other health endpoints in humans. Environ Res 108:177-184

Swan SH, Main KM, Liu F, Stewart SL, Kruse RL, Calafat AM, Mao CS, Redmon JB, Ternand CL, Sullivan S, Teague JL (2005) Decrease in anogenital distance among male infants with prenatal phthalate exposure. Environ Health Perspect 113:1056-1061

Vikelsøe J, Thomsen M, Johansen E (1998) Sources of phthalates and nonylphenols in municipal waste water. NERI Technical Report No. 225. National Environmental Research Institute, Denmark

Wang J, Liu P, Qian Y (1996) Biodegradation of phthalate acid ester by acclimated activated sludge. Environ Int 22:737-741

Wang J, Liu P, Qian Y (1999) Microbial metabolism of dibutyl phthalate (DBP) by a denitrifying bacterium. Process Biochem 34:745-749

Wang J, Liu P, Shi H, Qian Y (1997) Kinetics of phthalic acid ester degradation by acclimated activated sludge. Process Biochem 32:567-571

Xu XR, Li HB, Gu JD (2006) Elucidation of $n$-butyl benzyl phthalate biodegradation using high-performance liquid chromatography and gas chromatography-mass spectrometry. Anal Bioanal Chem 386:370-375

Xu XR, Li SX, Li XY, Gu JD, Chen F, Li XZ, Li HB (2009) Degradation of $n$-butyl benzyl phthalate by UV/TiO2. J Hazard Mater 164:527-532

Yeo S, Park N, Song HG, Choi HT (2007) Generation of a transformant showing higher manganese peroxidase (Mnp) activity by overexpression of Mnp gene in Trametes versicolor. J Microbiol 45:213-218

Yim B, Nagata Y, Maeda Y (2002) Sonolytic degradation of phthalic acid esters in aqueous solutions. Acceleration of hydrolysis by sonochemical action. J Phys Chem A 106:104-107

Yuan SY, Chang JS, Chang BV (2001) Biodegradation of phenanthrene in river sediment. Chemosphere 43:273-278

Yuan SY, Liu C, Liao CS, Chang BV (2002) Occurrence and microbial degradation of phthalate esters in Taiwan river sediments. Chemosphere 49:1295-1299 